\title{
THE USE OF VAGINAL AND RECTAL CULTURES IN THE MANAGEMENT OF GONORRHCA IN THE FEMALE
}

\author{
BY \\ A. E. WILKINSON \\ Assistant Pathologist, Whitechapel Clinic, London
}

The advent of such a potent and yet non-toxic drug as penicillin has necessitated a re-examination of all aspects of the management of gonorrhœa in the female. Recently there has been a marked tendency, especially in the United States, to shorten the post-treatment period of observation and bacteriological investigation before cure is presumed. Duncan and others (1945) used the criterion of at least three negative smears and cultures of the urethral and cervical secretions at forty-eight-hourly intervals after the completion of treatment. Thomas and Meyer (1945) carried out four examinations of the urethral and cervical secretions by smears and cultures on alternate days, starting the day following the completion of treatment. Van Slyke and Heller (1945) insisted on a minimum of ten days' post-treatment observation including at least three negative cultures. These periods refer only to the surveillance for gonorrhœa as distinct from the serological observation to detect incubating syphilis.

While such short observation periods have not been adopted in this country, their acceptance elsewhere serves to emphasize the importance of raising to the highest possible degree of efficiency the standards of the bacteriological investigations employed as tests of cure. The very number and variety of culture media which have been elaborated for the isolation of the gonococcus suggest strongly that the ideal medium has.not yet been discovered. Those in general use have been developed empirically, and further improvement of media must probably await a more precise knowledge of the growth requirements of the organism. But even with the media available examination of material from a wider range of potentially infected sites might be expected to raise the standards of results.

Investigations in routine tests are usually restricted to the cervix and urethra. Examination of the vaginal secretion. was recommended by King and Mascall (1935), but despite the excellent results obtained this practice does not appear to have been widely adopted. It has been recognized for a long time that the gonococcus may often be found in the rectum of females with genito-urinary gonorrhœa, the rectal involvement being sometimes symptomless. Vaginal cultures have been employed as a routine at the Whitechapel Clinic since 1935. During the past two years a large number of rectal smears and cultures have been examined and sufficient cases have now been accumulated to form an opinion as to the value of examination of material from these two sites in the diagnosis of gonorrhœa.

\section{Case Material and Methods Employed}

The results of all cultures and smears taken in the. female department of the Whitechapel Clinic in the twelve-month period from Oct. 1, 1947, to Sept. 30, 1948, form the basis of this study. Throughout this period the culture medium has consisted of nutrient agar enriched with hydrocele fluid in the proportion of 1 part of hydrocele to 4 of the agar base, the medium having a $p H$ within the range of $7 \cdot 4$ to $7 \cdot 6$. Besides the routine urethral and cervical smears and cultures, material from the posterior vaginal fornix has been examined in all cases. Cultures and smears from the rectal mucosa have been examined in the majority of new cases according to the technique described by Nicol (1948). Smears of vaginal secretion have not been examined as a routine as it had been found that they usually consisted of a mass of secondary organisms in which it was not possible to identify the gonococcus with certainty.

Cultures were incubated in air at $37^{\circ} \mathrm{C}$. for fortyeight hours and then flooded with a freshly prepared 1 per cent. aqueous solution of dimethyl $-p-$ phenylene diamine hydrochloride. Oxydase-positive colonies having typical colonial and microscopical morphology were provisionally accepted as gonoccoci. Isolation in pure culture and the study of fermentation reactions was attempted in doubtful cases or in cases in which legal issues were involved. Plate cultures were used only for a proportion of the vaginal cultures ; slopes were used for the remainder and for specimens from other sites. This was done to economize the medium in view of the difficulty experienced in obtaining adequate supplies of hydrocele fluid. 


\section{Results Obtained}

In the period under review 10,355 cultures from 3,179 cases were examined; these figures include both the initial diagnostic cultures in new cases and cultures taken during the period of observation after treatment. In 323 patients (10.16 per cent.) gonococci were found either in smears or cultures. Of this number 281 were either untreated patients or were patients in whom re-infection was considered to have occurred. Together these are subsequently referred to as Group A. The remaining forty-two patients, forming Group B, are those classed as treatment failures or relapses. A proportion of the so-called relapsed cases may have been re-infections, despite the denial of re-exposure, but a distinction has been made between the two groups for the purpose of analysing the results obtained. These are summarized in Table $I$.

TABLE I

ANALYSIS OF POSITIVE RESULTS

\begin{tabular}{|c|c|c|c|c|}
\hline & \multicolumn{2}{|c|}{$\begin{array}{l}\text { Group A : } \\
\text { Fresh cases } \\
\text { and re-in- } \\
\text { fections } \\
\text { (281 cases) }\end{array}$} & \multicolumn{2}{|c|}{$\begin{array}{l}\text { Group B : } \\
\text { Treatment } \\
\text { failures and } \\
\text { relapses } \\
\text { (42 cases) }\end{array}$} \\
\hline & No. & $\%$ & No. & $\%$ \\
\hline $\begin{array}{l}\text { Cultures positive } \ldots \\
\text { Smears positive } \ldots \\
\text { Smears and cultures positive } \\
\text { Cultures alone positive } \\
\text { Smears alone positive }\end{array}$ & $\begin{array}{r}256 \\
198 \\
173 \\
83 \\
25\end{array}$ & $\begin{array}{l}91 \\
70 \cdot 5 \\
61 \cdot 5 \\
29 \cdot 5 \\
9\end{array}$ & $\begin{array}{r}39 \\
23 \\
20 \\
19 \\
3\end{array}$ & $\begin{array}{r}93 \\
55 \\
47 \\
45 \\
7\end{array}$ \\
\hline
\end{tabular}

\section{Discussion}

The results obtained demonstrate the superiority of cultures over smears in the diagnosis of gonorrhœea. Without cultural examination 29.5 per cent. of the fresh cases and 45 per cent. of the relapsed cases might have been overlooked. The analysis of the sites of infection in Table II shows the marked preponderance of isolations from the cervix over those from other sites. These results are shown in diagrammatic form in the Figure.

Vaginal Infections.-It is interesting to compare the present results with those of King and Mascall (1935), which were obtained in the pre-chemotherapeutic era. They recommended the inoculation of large amounts of material from the posterior vaginal fornix on to plates of Price's egg albumen agar (Price, 1935). Analysis of their figures shows that from a total of 263 cases examined gonococci were found by smear and culture in 138. Of these 138 positive cases, urethral smears were positive in twenty-two cases ( 16 per cent.), and urethral cultures positive in forty-nine cases $(35.5$ per cent.) ; cervical smears were positive in seventeen cases (12 per cent.) and cervical cultures positive in thirty-three cases (24 per cent.). The percentages of isolations from these two sites are considerably below those obtained in the present series, and it is noteworthy that in the 1935 series the urethra was a more fruitful source of gonococci than the cervix-a reversal of the present findings. The vaginal plate technique gave positive results in ninety-eight cases (71 per cent.) as against 61 per cent. of isolations from this site in the present series. Plate cultures were used in a proportion of the cases under discussion, but their use did not increase the number of isolations. Thus, of ninetyfour cultures from positive patients on slopes, fiftysix (59.6 per cent.) were positive as against seventyone ( $60 \cdot 1$ per cent.) of 118 cases cultured on plates. Nevertheless it is felt that plates are preferable since a larger inoculum can be used and inspection and isolation of suspicious colonies are very much easier than when slopes are used.

In this series a diagnosis of gonorrhœa was made from vaginal cultures only (smears being negative) in five fresh and two relapsed cases.

TABLE II

ANALYSIS OF POSITIVE RESULTS BY SITES

\begin{tabular}{|c|c|c|c|c|c|c|c|c|}
\hline \multirow{3}{*}{ Site } & \multicolumn{4}{|c|}{ Group A : Fresh cases and re-infections } & \multicolumn{4}{|c|}{ Group B : Treatment failures and relapses } \\
\hline & \multicolumn{2}{|c|}{ Cultures } & \multicolumn{2}{|c|}{ Smears } & \multicolumn{2}{|c|}{ Cultures } & \multicolumn{2}{|c|}{ Smears } \\
\hline & $\begin{array}{c}\text { No. } \\
\text { Exam- } \\
\text { ined }\end{array}$ & Positive & $\underset{\text { Exam- }}{\text { No. }}$ & Positive & $\begin{array}{c}\text { No. } \\
\text { Exam- } \\
\text { ined }\end{array}$ & Positive & $\begin{array}{c}\text { No. } \\
\text { Exam- } \\
\text { ined }\end{array}$ & Positive \\
\hline Urethra .. & 280 & $172(61 \cdot 4 \%)$ & 280 & $126(45 \%)$ & 42 & $24(57 \%)$ & 42 & $12(28 \cdot 5 \%)$ \\
\hline Cervix .. & 274 & $217(79 \cdot 2 \%)$ & 277 & $140(50 \cdot 5 \%)$ & 42 & $30(71 \cdot 5 \%)$ & 42 & $14(33 \%)$ \\
\hline Vagina .. & 262 & $160(61 \%)$ & - & - & 40 & $17(42 \cdot 5 \%)$ & - & - \\
\hline Rectum .. & 216 & $39(18 \%)$ & 230 & $64(28 \cdot 1 \%)$ & 8 & $1(12 \cdot 5 \%)$ & 13 & $4(32 \cdot 5 \%)$ \\
\hline
\end{tabular}




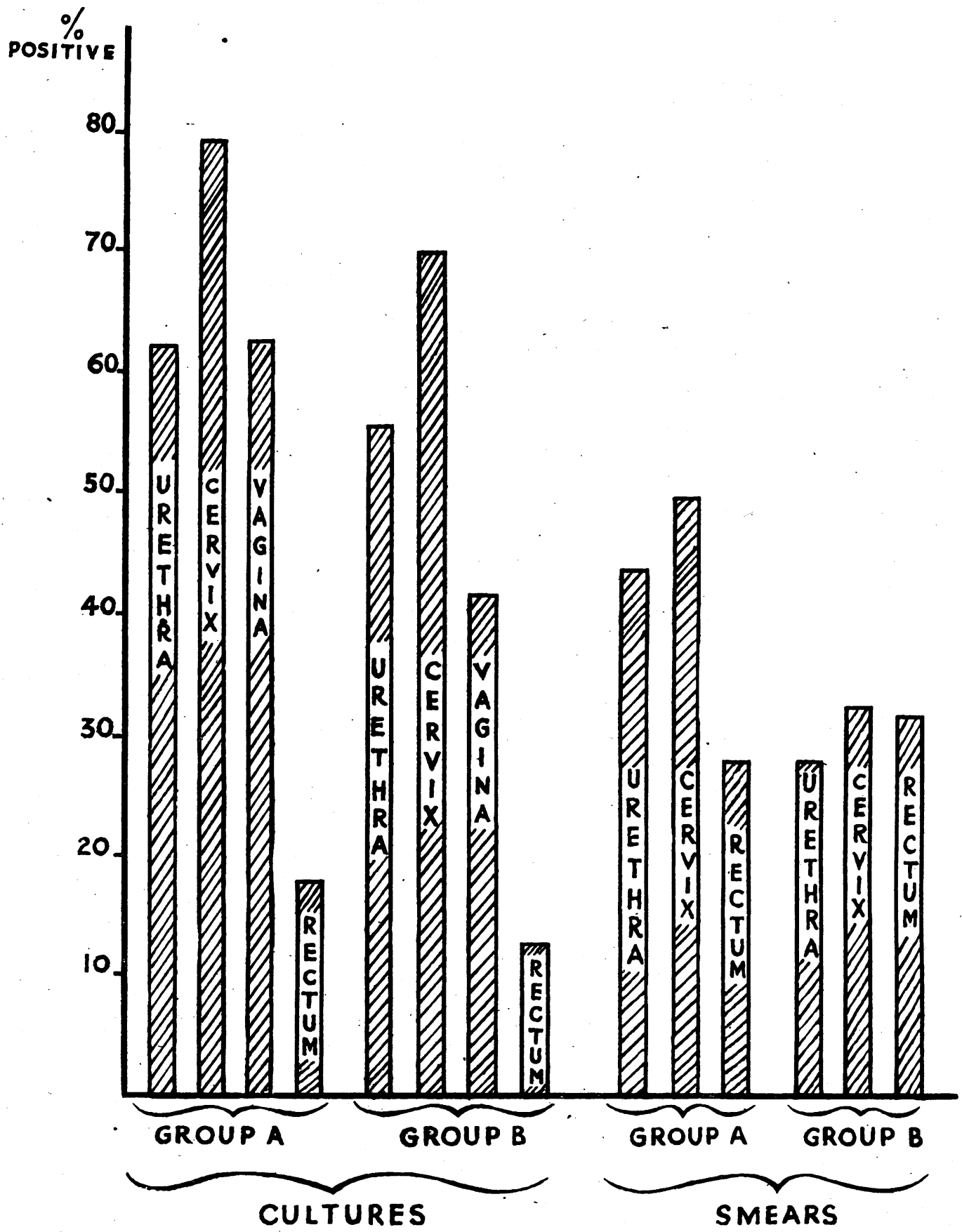

FIGURE, - Cultures and smears at the various sites. 
Rectal Infections.-The occurrence of symptomless gonococcal infection of the rectum in females is well established. Clements and Hughes (1935) examined 160 cases by cultural methods and found sixty-nine (43 per cent.) positive. Nicol (1948) in a previous series from this Clinic examined seventyfour consecutive patients and in twenty-six found gonococci, smears alone being positive in twentyone cases, cultures alone in three cases, and both smears and cultures positive in two cases. Only eight of the patients admitted to any rectal symptoms and these were discovered only after careful questioning.

In the present series of cases combining Groups $A$ and B, rectal cultures were taken from 224 patients suffering from gonorrhœa, and forty $(17 \cdot 8$ per cent.) were found to be harbouring gonococci. In a few cases these were isolated in pure culture and their identity confirmed by fermentation reactions. Examination of smears (the majority of which were examined by the medical officers of the Clinic) gave a higher proportion of positive results ; of 243 examined, sixty-eight ( 28 per cent.) showed pus cells with gram-negative intracellular diplococci having the morphological appearance of gonococci. In the fresh cases of Group A the diagnosis of gonorrhœa was based on a positive rectal culture with negative smears in one case ; in an additional five cases smears were also positive -three of them in the rectal smear only. Seven cases showed a positive rectal smear only, all the cultures being negative; and in another nine cases the rectal smear alone was positive in addition to positive cultures from other sites.
It is recognized that the present method of rectal culture is imperfect ; a heavy growth of the normal rectal flora is usually obtained and if gonococci are scanty they are readily overgrown. The development of a selective medium which would favour the growth of gonococci at the expense of the rectal flora is desirable, and it is hoped to explore this possibility. But even the present crude culture methods revealed the presence of gonococci in an important proportion of the cases examined, and, since they are in an environment where penicillin given parenterally might well be destroyed by the penicillinase produced by the normal inhabitants of the bowel, their significance as a possible nidus from which infection might spread may be of importance.

\section{Summary}

1. The results of the examination of 10,355 cultures for gonococci from female patients are presented and analysed.

2. The results and advantages of eultures from the vagina and rectum are discussed and their importance as an adjuvant means of diagnosis is stressed.

\section{REFERENCES}

Clements, P. A., and Hughes, K. E. A. (1935). Lancet, $2,18$.

Duncan, E. T., Zobel, R. L., and Hutcheson, R. H.

(1945). J. vener. Dis. Inf., 26, 49.

King, A. J., and Mascall, W. N. (1935). Lancet, 1, 1492.

Nicol, C. S. (1948). Brit. J. vener. Dis., $24,26$.

Price, I. N. O. (1935). J. Path. Bact., 40, 345.

Thomas, R. B., and Meyer, E. (1945). J. vener. Dis. Inf., $26,94$.

Van Slyke, C. J., and Heller, J. R. (1945). Ibid., 26, 98. 